\begin{tabular}{c} 
Brazilian Journal \\
of Chemical \\
Engineering \\
\hline
\end{tabular}

ISSN 0104-6632

Printed in Brazil

www.abeq.org.br/bjche

Vol. 31, No. 02, pp. 271 - 285, April - June, 2014

dx.doi.org/10.1590/0104-6632.20140312s00002616

\title{
BIODIESEL PRODUCTION THROUGH NON-CATALYTIC SUPERCRITICAL TRANSESTERIFICATION: CURRENT STATE AND PERSPECTIVES
}

\author{
C. da Silva ${ }^{1 *}$ and J. Vladimir Oliveira ${ }^{2}$ \\ ${ }^{1}$ Department of Technology, Phone: + (55) (44) 36219335, Fax: + (55) (44) 36219326, \\ Maringá State University, UEM, 87506-370, Umuarama - PR, Brazil. \\ E-mail: camiladasilva.eq@gmail.com \\ ${ }^{2}$ Department of Chemical and Food Engineering, UFSC, 88040-900, Florianópolis - SC, Brazil. \\ (Submitted: March 20, 2013 ; Revised: October 2, 2013 ; Accepted: October 2, 2013)
}

\begin{abstract}
The inconveniences of the conventional method for biodiesel production by alkaline catalysis suggests research towards alternative methods, with the non-catalytic transesterification using an alcohol at supercritical conditions proposed as a promising technique for biodiesel production. The so-called supercritical method (SCM) has powerful advantages over conventional techniques, such as fast reaction rates, feedstock flexibility, production efficiency and environmentally friendly benefits. However, application of this methodology has some limitations, like operating conditions (elevated temperature and pressure and higher amounts of alcohol), which result in high energy costs and degradation of the products generated. In this review paper the state of the art in relation to the use of the SCM for biodiesel production is reported and discussed, describing the characteristics of the method, the influence of operational parameters on the ester yield, patents available in the field and the perspectives for application of the technique.

Keywords: Non-catalytic; Transesterification; Supercritical method; Biodiesel; Vegetable oils.
\end{abstract}

\section{INTRODUCTION}

Research into alternative sources of renewable energy has been largely stimulated by the increasing energetic demand and the need to gradually reduce the consumption of fossil fuels on account of their detrimental effect on the environment. Biodiesel, fatty acid ethyl (FAEE) or methyl (FAME) esters, has been recognized as a relevant alternative fuel to mineral diesel, either as an additive or replacement, because of the well-known environmental and economical benefits. Its merits include a non-toxic, biodegradable, domestically produced and renewable resource (Srivastava and Prasad, 2000; Fukuda et al., 2001; Meher et al., 2006). Besides, this biofuel has a cetane number higher than diesel from petroleum and a better combustion emissions profile, such as reduced levels of particulate matter and carbon monoxide and, under some conditions, nitrogen oxides (Altin et al., 2001; McCornick et al., 2001; Meher et al., 2006).

The most common way to produce biodiesel is widely known to be via a transesterification reaction (Srivastava and Prasad, 2000), which is conventionally performed using alkaline, acid or enzyme catalysts (Meher et al., 2006). The conventional alkalicatalyzed process affords high levels of conversion of triglycerides to their corresponding fatty acid alkyl esters in short reaction times, but has some disadvantages such as the large volume of waste water generated and feedstock flexibility (Meher et al., 2006; Abbaszaadeh et al., 2012). Transesterification

*To whom correspondence should be addressed 
using acid catalysts is known to be much slower than alkali catalysis, may lead to the formation of undesirable by-products, with difficult separation steps, and requires careful removal of catalyst from the biodiesel fuel since acid catalyst residues can damage engine parts (Zhang et al., 2003; Vyas et al., 2010; Abbaszaadeh et al., 2012). This is one of the main reasons why most biodiesel standard specifications place a very low maximum limit on acid value for the final product. In an attempt to overcome the drawbacks of chemical-catalyzed processes, the use of heterogeneous catalysts (chemical or enzymatic) has been suggested.

The use of heterogeneous catalysts in alcoholysis of vegetable oils reduces the difficulties of separation of products and catalyst, resulting in the generation of lower effluent volume and reuse (Helwani et al., 2009; Abbaszaadeh et al., 2012). Current literature suggests the use of various acid and basic heterogeneous catalysts, with catalyst reuse; however, heterogeneous chemical catalysis generally shows low yields compared to homogeneous alkaline catalysis (Helwani et al., 2009; Kiss et al., 2010). The use of enzyme-catalyzed transesterification methods has some drawbacks. Enzyme activity losses may occur due to deleterious alcohol effects, water deactivation and glycerol inhibition (Fukuda et al., 2001; Ranganathan et al., 2008). Moreover, the high cost of enzyme production still remains the major obstacle to commercialization of enzyme-catalyzed processes.

To minimize these drawbacks, a catalyst-free technique for the transesterification of vegetable oils using an alcohol under supercritical conditions has been proposed, keeping the benefits of fuel quality and taking into account environmental concerns (Kusdiana and Saka, 2001; Demirbas, 2002; Warabi et al., 2004). According to the current literature, catalyst-free alcoholysis reactions at high temperature and pressure conditions provide improved phase solubility and decreased mass-transfer limitations. The reaction rate increases significantly in the supercritical state and thus the reaction is complete in shorter periods with consequent simpler separation and purification steps (Kusdiana and Saka, 2001). In supercritical conditions, the alcohol is not only a reactant but also an acid catalyst (Kusdiana and Saka, 2004a). Besides, it has been shown that the supercritical method (SCM) is more tolerant to the presence of water and free fatty acids than the conventional alkali-catalyzed technique. Hence the technique is much more flexible to various types of vegetable oils, which increases the interest in research involving the application of this methodology.
The economic analysis of the processes for biodiesel production using homogeneous alkaline catalysis and SCM has been reported (Glisic and Skala, 2009; Deshpande et al., 2010). It was noted that energy consumption is extremely similar in both cases. In the SCM the heating step involves high energy consumption, but costs are compensated by the simpler purification step of the products, requiring lower power consumption, which is a high cost step of the actual conventional process. Marchetti and Errazu (2008) evaluated different processes for biodiesel production using vegetable oils with high content of free fatty acids and stated that the SCM is an attractive alternative from a technological point of view. Additionally, from the economic point of view, less waste water is produced and a high quality glycerin is generated as a byproduct; however, higher energy is required by the reaction step.

The production costs of biodiesel can be minimized by the sale of the by-products generated. However, when using the conventional alkali-catalyzed technique, traces of catalyst can be found in the glycerin, which limits the use of this product. Thus, subsequent purification steps are required, which is no longer required in the SCM, with generation of a high-grade glycerin (Kusdiana and Saka, 2001; Demirbas, 2002).

The reaction for biodiesel production under supercritical conditions requires high alcohol to oil molar ratios and the adoption of high temperatures and pressures for the reaction to present satisfactory conversion levels, leading to high processing costs and causing, in many cases, the degradation of the fatty acid esters formed and reaction of the glycerol formed with other components of the reaction medium, hence decreasing the reaction conversion. The current literature points to some alternatives to reduce the expected high operating costs and product degradation. Such strategies usually involve: (i) addition of co-solvents; (ii) the use of heterogeneous catalysts; (iii) a two-step process with glycerol removal in the first step; (iv) a two-step process comprising hydrolysis of triglycerides in subcritical water and subsequent esterification of fatty acids; (v) the use of different reactor configurations with increased mass transfer operating in continuous mode (microreactor or packed bed reactor).

Taking into account the literature survey, the aim of this work is to provide a brief review on the production of biodiesel by a non-catalytic process under supercritical conditions. This review focuses on the research on biodiesel production, evaluating the role of process variables such as temperature, pressure, oil to alcohol molar ratio and residence 
time. The different configurations of reaction systems, alternatives to reduce the high process conditions, the effect of water and free fatty acids in the reaction medium, decomposition of fatty acids and a compilation of main patents registered for the use of this method are evaluated.

\section{EFFECT OF PROCESS VARIABLES ON REACTION YIELD}

The non-catalytic transesterification of vegetable oils is characterized by the use of an alcohol under supercritical conditions. The literature presents several studies using this methodology, in which the effect of process variables on the yield of the reaction is evaluated using different feedstocks with different reactor configurations. The experimental conditions set for obtaining high yields by SCM are summarized in Table 1.

\section{Temperature}

Studies in the literature show that the reaction temperature is the most critical parameter for determining the extent of reaction, especially across the critical temperature of methanol $(513 \mathrm{~K})$ and ethanol $(514 \mathrm{~K})$. Generally, an increase in temperature leads to a sharp enhancement of reaction conversions and faster initial reaction rates, but at elevated temperatures $(>623 \mathrm{~K})$ a decrease in reaction yield is observed (Minami and Saka, 2006; He et al., 2007; Silva et al., 2007). The literature reports that the best reaction temperature depends on the length and degree of saturation of the fatty acid chains of the oil (Vieitez et al., 2012).

Table 1: Experimental conditions for the best reaction conversion of vegetable oil to esters with SCM.

\begin{tabular}{|c|c|c|c|c|c|c|c|}
\hline Reference & $\mathbf{T}(\mathbf{K})$ & $\mathbf{P}(\mathbf{M P a})$ & $\begin{array}{c}\text { Oil to Alcohol } \\
\text { molar ratio }\end{array}$ & \begin{tabular}{|c|} 
Reaction \\
time (min)
\end{tabular} & $\begin{array}{c}\text { Oil type/alcohol/additional } \\
\text { information }\end{array}$ & $\begin{array}{c}\text { Reactor } \\
\text { type }\end{array}$ & Esters \\
\hline Kusdiana and Saka (2001) & 623 & 45 & $1: 42$ & 4 & rapeseed/methanol & BR & $>95 \mathrm{wt} \%$ content \\
\hline Demirbas (2002) & 623 & $\mathrm{~N} / \mathrm{R}$ & $1: 41$ & 5 & cottonseed/methanol & $\mathrm{BR}$ & $95 \mathrm{wt} \%$ content \\
\hline Cao et al. (2005) & 593 & $\mathrm{~N} / \mathrm{R}$ & $1: 33$ & 10 & $\begin{array}{l}\text { soybean/methanol/ propane to } \\
\text { methanol molar ratio of } 1: 10\end{array}$ & $\mathrm{BR}$ & $95 \mathrm{wt} \%$ content \\
\hline Wang et al. (2008) & 593 & 15 & $1: 40$ & 20 & soybean/methanol & $\mathrm{BR}$ & $\sim 70 \mathrm{wt} \%$ yield \\
\hline $\begin{array}{l}\text { Olivares-Carrillo and } \\
\text { Quesada-Medina (2011a) }\end{array}$ & 623 & 43 & $1: 43$ & $\sim 30$ & soybean/methanol & $\mathrm{BR}$ & $\sim 80 \mathrm{wt} \%$ yield \\
\hline Tan et al. (2010) & 623 & $\mathrm{~N} / \mathrm{R}$ & $1: 40$ & 20 & palm/methanol & $\mathrm{BR}$ & $\sim 80 \mathrm{wt} \%$ yield \\
\hline Lee et al. (2012) & 543 & $\sim 10$ & 1:1 (mass ratio) & 45 & waste canola & $\mathrm{BR}$ & $96.4 \mathrm{wt} \%$ yield \\
\hline Minami and Saka (2006) & 623 & 20 & $1: 42$ & 30 & rapeseed/methanol & TR & $87 \mathrm{wt} \%$ content \\
\hline He et al. (2007) & 583 & 32 & $1: 40$ & 25 & soybean/methanol & TR & $77 \mathrm{wt} \%$ content \\
\hline Silva et al. (2007) & 623 & 20 & $1: 40$ & 35 & soybean/ethanol & $\mathrm{TR}$ & $\begin{array}{r}80 \mathrm{wt} \% \\
\text { conversion } \\
\end{array}$ \\
\hline Vieitez et al. (2009) & 573 & 20 & $1: 40$ & 28 & $\begin{array}{l}\text { soybean/ethanol/water content } \\
\text { of } 5 \mathrm{wt} \%\end{array}$ & TR & $\begin{array}{r}70 \mathrm{wt} \% \\
\text { conversion }\end{array}$ \\
\hline Bertoldi et al. (2009) & 598 & 20 & $1: 40$ & 110 & $\begin{array}{l}\text { soybean/ ethanol/ } \mathrm{CO}_{2} \text { to } \\
\text { substrate mass ratio of } 0.05: 1\end{array}$ & TR & $\sim 76 \mathrm{wt} \%$ yield \\
\hline Vieitez et al. (2010) & 573 & 20 & $1: 40$ & 52.5 & $\begin{array}{l}\text { Degummed } \\
\text { soybean } / \text { methanol/ } \\
\text { water content of } 10 \mathrm{wt} \%\end{array}$ & TR & $\sim 80 \mathrm{wt} \%$ content \\
\hline Silva et al. (2010) & 598 & 20 & $1: 20$ & 45 & soybean oil/ethanol & MR & $\sim 70 \mathrm{wt} \%$ yield \\
\hline Vieitez et al. (2011) & 573 & 20 & $1: 40$ & 28 & $\begin{array}{l}\text { castor oil/ethanol/ water } \\
\text { content of } 5 \mathrm{wt} \%\end{array}$ & & $\sim 75 \mathrm{wt} \%$ content \\
\hline Trentin et al. (2011a) & 598 & 20 & $1: 20$ & 45 & $\begin{array}{l}\text { soybean oil/ethanol/ } / \mathrm{CO}_{2} \text { to } \\
\text { substrate mass ratio of } 0.2: 1\end{array}$ & MR & $\sim 80 \mathrm{wt} \%$ yield \\
\hline Choi et al. (2011) & 623 & 35 & $1: 40$ & $\sim 15$ & palm olein/methanol & TR & $\sim 85 \mathrm{wt} \%$ yield \\
\hline Sawangkeaw et al. (2011) & 673 & 15 & $1: 21$ & 10 & palm/ethanol & TR & $\sim 75 \mathrm{wt} \%$ content \\
\hline Vieitez et al. (2012) & 573 & 20 & $1: 40$ & $\sim 49$ & $\begin{array}{l}\text { soybean oil with } 10 \mathrm{wt} \% \text { of } \\
\text { FFAs/ethanol }\end{array}$ & TR & $\sim 90 \mathrm{wt} \%$ content \\
\hline Velez et al. (2012) & 593 & 15 & $1: 40$ & 45 & soybean oil/ethanol & TR & $\sim 80 \mathrm{wt} \%$ content \\
\hline
\end{tabular}

N/R: not reported; FFAs: free fatty acids; BR: batch reactor; TR: tubular reactor; MR: microtube reactor. 
Kusdiana and Saka (2001) studied the effects of temperature on the reaction rate from $473 \mathrm{~K}$ to $760 \mathrm{~K}$ and showed that the rate constant increased with temperature. At temperatures of 473 and $503 \mathrm{~K}$ the conversion of triglyceride to methyl esters is relatively low due to the subcritical state of methanol. Similar results regarding the effect of temperature were reported by other researchers for reactions in batch and continuous mode. For the batch mode transesterification of soybean oil in supercritical methanol with 50 min of reaction and using an oil to methanol molar ratio of 1:43, Olivares-Carrillo and Quesada-Medina (2011a) reported ester yields of $\sim 65 \mathrm{wt} \%$ and $\sim 20$ $\mathrm{wt} \%$ at $523 / 12 \mathrm{MPa}$ and $573 \mathrm{~K} / 26 \mathrm{MPa}$, respectively. For the reaction in continuous mode, Choi et al. (2011) reported a positive effect of temperature in the range of 543 to $623 \mathrm{~K}$ on the FAME yield for reaction performed in a plug flow reactor at $35 \mathrm{MPa}$, $25 \mathrm{~min}$ and palm olein oil to methanol molar ratio of $1: 40$, with yields of $55 \mathrm{wt} \%$ and $80 \mathrm{wt} \%$ at $563 \mathrm{~K}$ and $603 \mathrm{~K}$, respectively. In the transesterification of castor oil in a tubular reactor at $20 \mathrm{MPa}, 42 \mathrm{~min}$ of residence time and using oil to ethanol molar ratio of 1:40, Vieitez et al. (2011) obtained about $28 \mathrm{wt} \%$ and $42 \mathrm{wt} \%$ of FAEE for $573 \mathrm{~K}$ and $598 \mathrm{~K}$ respectively. Vieitez et al. (2009) reported about $22 \mathrm{wt} \%$ and $46 \mathrm{wt} \%$ under the same operating conditions for soybean oil as raw material. For the supercritical transesterification of soybean oil in the continuous microtube reactor, Silva et al. (2010) achieved yields at $45 \mathrm{~min}$ of reaction, $20 \mathrm{MPa}$ and 1:20 (oil to ethanol molar ratio) on the order of $50 \mathrm{wt} \%$ at $573 \mathrm{~K}$ and 70 wt $\%$ at $598 \mathrm{~K}$.

\section{Pressure}

The system pressure may have a great influence on the properties of a supercritical fluid near its critical point, such as density, self-diffusivity, hydrogen bound intensity, viscosity, etc. When the pressure was slightly higher than the critical pressure of ethanol ( 6.4 MPa), the yield was lower than at high pressure (Trentin et al., 2011a). Most studies on SCM are reported in the batch mode and the effect of this variable on reaction yield is not presented as the pressure is only monitored during the reaction (Kusdiana and Saka, 2001; Demirbas, 2002; Warabi et al., 2004). In a batch-type reactor, the pressure depends on the temperature of the experiment, the alcohol to oil ratio and the amount of reactants (Boer and Bahri, 2011). For controlling this process variable, reactors operated in continuous mode were developed with pressure controlled by a valve at the end of the reactor (Pinnarat and Savage, 2008; Boer and Bahri, 2011) and it was reported that the highest admissible pressure for the supercritical transesterification reaction is $20 \mathrm{MPa}$ (Minami and Saka, 2006; Silva et al. 2007; Silva et al., 2010; Trentin et al., 2011a). In the literature, researchers believe that operation pressures above $20 \mathrm{MPa}$ may not be industrially viable, increasing the implementation costs for biodiesel production by the supercritical transesterification method (Bertoldi et al., 2009; Silva et al., 2010; Trentin et al., 2011a).

He et al. (2007) evaluated the effect of pressure on the continuous transesterification of soybean oil with methanol and observed a positive effect in the range of 10-40 MPa, with the best condition found at $35 \mathrm{MPa}$. Bertoldi et al. (2009) evaluated the effect of pressure on the continuous transesterification of soybean oil with ethanol and carbon dioxide as cosolvent and observed a positive effect in the range of 7.5-20MPa for a co-solvent to substrate mass ratio of $0.05: 1$. In investigating the reaction of soybean oil with ethanol conducted in a microtube reactor, Silva et al. (2010) found at $573 \mathrm{~K}$, oil to ethanol molar ratio of 1:20 and 45 minutes of residence time, approximately $52 \mathrm{wt} \%$ and $36 \mathrm{wt} \%$ of FAEE yield at $20 \mathrm{MPa}$ and $10 \mathrm{MPa}$, respectively. For the reaction with addition of carbon dioxide as co-solvent conducted in a microtube reactor, Trentin et al. (2011a) obtained about $52 \mathrm{wt} \%$ and $72 \mathrm{wt} \%$ for the same conditions, respectively, at $10 \mathrm{MPa}$ and $20 \mathrm{MPa}$. Conversely, Bunyakiat et al. (2006) observed that pressure did not affect the transesterification conversion of coconut oil with supercritical methanol.

\section{Oil to Alcohol Molar Ratio}

The oil to alcohol molar ratio is one of the most important variables affecting the yield of fatty acid esters in the supercritical method because in catalystfree reactions an increase in the oil to alcohol molar ratio should allow greater contact between substrates, thus favoring reaction conversion (Kusdiana and Saka, 2001). The transesterification reaction requires a stoichiometric oil to alcohol molar ratio of $1: 3$, while the operating ratio in supercritical alcohol conditions varies from 1:3 to 1:60.

Kusdiana and Saka (2001) and Demirbas (2002) evaluated the influence of the oil to methanol molar ratio in non-catalytic transesterification in batch mode and obtained the best results in terms of conversion to esters for the condition of an oil to methanol molar ratio of 1:42. He et al. (2007) evaluated the effect of the alcohol to oil molar ratio on the continuous transesterification of soybean oil in supercritical methanol and found that, at $573 \mathrm{~K}$ and $32 \mathrm{MPa}$, the oil to 
methanol molar ratio showed a positive effect on reaction conversion in the range of 1:6-1:40. At oil to methanol molar ratios of 1:20 and 1:40 yields on the order of $64 \mathrm{wt} \%$ and $70 \mathrm{wt} \%$ in methyl esters are reported by the authors. The effect of oil to ethanol molar ratio was also studied by Sawangkeaw et al. (2011) for the transesterification of palm oil in batch mode using supercritical ethanol at $673 \mathrm{~K}, 10 \mathrm{~min}$ of reaction and $15 \mathrm{MPa}$; they reported an increase in the reaction conversion with increasing oil to ethanol molar ratio of in the range of $1: 3$ to $1: 24$ and ester content of $60 \mathrm{wt} \%$ at $1: 12$ and about $78 \mathrm{wt} \%$ at $1: 21$. In the ethanolysis of soybean oil at oil to ethanol molar ratio of $1: 20,20 \mathrm{MPa}, 573 \mathrm{~K}$ and 45 of residence time, Silva et al. (2010) obtained yields on the order of $50 \mathrm{wt} \%$, while for an oil to methanol molar ratio of 1:40 the authors report $58 \mathrm{wt} \%$ conversion of soybean oil to ethyl esters. Lee et al. (2012) evaluated the effect of the oil to methanol molar ratio on the transesterification of waste canola oil in batch mode and found that the oil to methanol molar ratio showed a positive effect on the methyl ester yield in the range of 1:20 - 1:40. For oil to methanol molar ratios of 1:20 and 1:40 yields on the order of 4.4 $\mathrm{wt} \%$ and $24.5 \mathrm{wt} \%$ in methyl esters are reported by the authors at $517 \mathrm{~K}$ and $45 \mathrm{~min}$ of reaction. OlivaresCarrillo and Quesada-Medina (2012) reported that the oil to methanol molar ratio in the supercritical transesterification favored the formation of both saturated and unsaturated fatty acid methyl esters and had some protective effect on the thermal decomposition of the polyunsaturated esters.

\section{Content of Free Fatty Acids (FFAs) and Water in the Feedstock}

The feedstock flexibility is one of the most important advantages of SCM for biodiesel production because the final biodiesel price strongly depends on the feedstock value (Lam et al., 2010). In fact, the cost of the raw materials currently represents about $70 \%$ of the total production cost (RoblesMedina et al., 2009). The FFAs and water exert a negative effect on the conventional homogeneous alkali-catalyzed reaction, but can be successfully tolerated in the transesterification reaction using an alcohol at its supercritical conditions. The presence of FFAs in low cost feedstocks for biodiesel production makes alkaline-catalyzed transesterification unfeasible because of the consumption of catalyst by FFAs and soap formation if water is present in the feed, with consequent hydrolysis of the alkyl esters produced. In the alkaline-catalyzed transesterification, the water content must be less than $0.06 \mathrm{wt} \%$ and the FFAs content $0.5 \mathrm{wt} \%$ for satisfactory reaction yields (Meher et al., 2006; Vyas et al., 2010).

Currently, the main resource for biodiesel production in Brazil is soybean oil, comprising about $80 \%$ of total feedstock (ANP, 2011). However, recently, raw material price increases have motivated the use of other sources for achieving a future global leadership of the country in biodiesel production and the use of non-edible and waste oils with low-added value. These alternative feedstocks show high FFAs content in many cases, highlighting the use of the supercritical method for processing purposes. The presence of FFAs and water in the feedstocks causes three types of reactions (transesterification and hydrolysis of triglycerides, and esterification of FFA) to occur simultaneously under supercritical conditions (Kusdiana and Saka, 2004a).

The esterification reaction is faster than transesterification and ensures that all FFAs in the feedstocks, whether present originally or products of hydrolysis, are completely reacted into esters (Kusdiana and Saka, 2004a; Warabi et al., 2004). The difference in reaction rate between FFAs and triglycerides is possibly due to the reaction mechanism. The transesterification reaction is a stepwise reaction with the third and final step (conversion of monoglycerides to FAME) believed to be the rate limiting step. On the other hand, FFAs esterification has only one step (Boer and Bahri, 2011). Literature reports the influence of the FFAs content on the reaction medium of non-catalytic transesterification. Tan et al. (2010) showed that, with the presence of up to $28 \mathrm{wt} \%$ of FFAs in the reaction of palm oil with methanol, the reaction yield was maintained at $80 \mathrm{wt} \%$ at $623 \mathrm{~K}$, oil to methanol molar ratio of 1:40 and 20 minutes of reaction. In the work of Vieitez et al. (2012), the authors added FFAs to soybean oil and hence a higher FAEE yield was obtained.

Regarding the water content, Kusdiana and Saka (2004a) reported that the reaction under supercritical conditions was not affected by the water content in the reaction medium. Therefore, the presence of water in the reaction medium showed a favorable effect on the ester synthesis, due to its possible catalytic role for the transesterification process (Vieitez et al., 2009). At $598 \mathrm{~K}, 1: 40$ (soybean oil to ethanol molar ratio), $52.5 \mathrm{~min}$ of reaction and $20 \mathrm{MPa}$, Vieitez et al. (2009) reported ethyl esters content about $55 \mathrm{wt} \%$ for $0 \mathrm{wt} \%$ of water and $70 \mathrm{wt} \%$ for $5 \mathrm{wt} \%$ of water. For ethanolysis of castor oil in continuous mode, Vieitez et al. (2011) showed under same conditions, but at $573 \mathrm{~K}, 38 \mathrm{wt} \%, 62 \mathrm{wt} \%$ and $64 \mathrm{wt} \%$ of ethyl esters content for $0 \mathrm{wt} \%, 5 \mathrm{wt} \%$ and $10 \mathrm{wt} \%$ of water in the reaction medium, respectively. For continuous 
production of esters form sunflower oil, Velez et al. (2012) reported about $75 \mathrm{wt} \%$ and $88 \mathrm{wt} \%$ of FAEE content at $593 \mathrm{~K}, 1: 40$ (oil to ethanol molar ratio) and $30 \mathrm{~min}$ of residence time for $0 \mathrm{wt} \%$ and $4 \mathrm{wt} \%$ of water, respectively.

\section{DECOMPOSITION OF FATTY ACIDS}

During supercritical transesterification, the high temperatures (above $573 \mathrm{~K}$ ) employed and long reaction periods generally cause a decrease in the ester content. Different studies report the reasons for this fact - He et al. (2007) evaluated the results obtained for the transesterification of soybean oil in supercritical methanol and concluded that the reason for the decrease in reaction yield is the decrease in the content of unsaturated esters, caused by isomerization, hydrogenation and thermal decomposition that consume such esters, especially C18:2 (linoleic) and C18:3 (linolenate) that are more susceptible to thermal decomposition compared to mono-unsaturated and saturated esters. Imahara et al. (2008) evaluated the thermal stability of different samples of biodiesel and fatty acid esters under different conditions and found that thermal degradation is more pronounced for the unsaturated esters above $573 \mathrm{~K}$ and $19 \mathrm{MPa}$ and thermal stability of saturated esters is also affected. In order to evaluate the existence of thermal decompostion in the soybean oil transesterification with supercritical methanol, Olivares-Carrillo and Quesada-Medina (2011b) reported the evolution of the molar ratio between methyl linoleate and methyl palmitate (the main unsaturated and saturated FAMEs generated, respectively); the results showed that the molar ratio between these FAMEs decreased with the reaction time at $573 \mathrm{~K} / 26 \mathrm{MPa}$ and above: the higher the temperature, the lower the molar ratio. Vieitez et al. (2008) showed that the trans isomer content increases with increasing reaction temperature and residence time for soybean oil ethanolysis under supercritical conditions. Kasim et al. (2009) reported that the percentage of trans isomers can reach levels up to $16 \%$ under certain reaction conditions $(30 \mathrm{MPa}, 573 \mathrm{~K})$ for the transesterification of rice bran oil in supercritical methanol.

Vieitez et al. (2008) utilized the term "decomposition" of fatty acids to refer to the decrease in their percentage due to the formation of other compounds (not necessarily implying that they have decomposed but have suffered some type of alteration). Using this definition, this research group reported at $623 \mathrm{~K}, 20 \mathrm{MPa}$, oil to ethanol molar ratio of $1: 40$ and 42 minutes of residence time $\sim 62.0 \mathrm{wt} \%$
(Vieitez et al., 2009), $73 \mathrm{wt} \%$ (Vieitez et al., 2011), $\sim 8.0 \mathrm{wt} \%$ (Vieitez et al., 2012) and $\sim 16.0 \mathrm{wt} \%$ (Vieitez et al., 2012) for reactions with soybean oil, castor oil, rice bran oil and high oleic sunflower oil, respectively. Olivares-Carrillo and Quesada-Medina (2011a) obtained about $30 \mathrm{wt} \%$ of fatty acid decomposition for reactions of soybean oil in batch mode conducted at $623 \mathrm{~K}, 43 \mathrm{MPa}$, oil to methanol molar ratio of $1: 43$ and 90 minutes of reaction. Silva et al. (2010) reported the effect of process variables on the decomposition of fatty acids and results indicated that increasing the pressure and temperature favors product decomposition. He et al. (2007) reported that gradual heating of the reaction medium from the inlet to the outlet of the tubular reactor minimized the thermal decomposition of polyunsaturated fatty acid methyl esters, leading to increased yield of biodiesel.

Under alcohol supercritical conditions, side reactions with the participation of the glycerol formed as byproduct can cause the degradation of other components present in the reaction medium. Anistescu et al. (2008) performed alcoholysis reactions using supercritical methanol at temperatures around 623$673 \mathrm{~K}$ and reported the absence of glycerol in the reaction products; the authors cogitated that reaction of glycerol with other compounds may have occurred. Aimaretti et al. (2009) evaluated the reaction of refined soybean oil with supercritical methanol under different conditions. In the conditions studied by the authors, glycerol was not formed. It was reported that glycerol is converted into lower molecular weight products and water at the beginning of the reaction and that water reacts with triglycerides to form FFAs. In the course of the reaction, these FFAs are converted into methyl esters. Also, the glycerol may react in different ways: (i) decomposition of products of lower molecular weight, such as acrolein, acetaldehyde, acetic acid, among others, (ii) polymerization to form polyglycerols and (iii) etherification with methanol to produce ethers of glycerol, thus consuming the alcohol in the reaction medium. Marulanda et al. (2010) reported that the byproduct glycerol is thermally decomposed or is consumed upon formation by methanol to produce ethers under supercritical conditions. in the synthesis of biodiesel from waste canola oil, Lee et al. (2012) reported that a side reaction was obtained by reacting glycerol and supercritical methanol at $543 \mathrm{~K} / 10 \mathrm{MPa}$. The experimental results showed that these reactions could positively affect the overall biodiesel yield by providing oxygenated compounds such as 3-methoxy1,2-propanediol, dimethoxymethane, and 2,2-dimethoxypropane, as well as methyl palmitate and methyl 
oleate. In the study of Shin et al. (2011), the formation of hydrocarbons was reported in supercritical methanol as a result of the pyrolysis of methyl esters.

\section{INNOVATIVE TECHNOLOGY IN BIODIESEL PRODUCTION BY SCM}

As observed from the studies presented in Table 1, high transesterification yields require high temperature, high pressure and high alcohol to oil molar ratio. Indeed, high temperature and pressure require high initial investments (equipment costs) for the implementation of such processes and safety management policy. As a result of the high alcohol to oil molar ratio, greater energy consumption in the reactant preheating and recycling steps is unavoidable. Moreover, the high amount of alcohol in the biodiesel product retards the biodiesel-glycerol phase separation. Therefore, the use of those original parameters results in high capital costs, especially for the reactor and pump, being somewhat higher than for the novel catalytic methods (Ngamprasertsith and Sawangkeaw, 2010). To increase the technical and economical feasibility of supercritical method, further studies are required to reduce the energy consumption and operating parameters of this process.

Some works reported different process synthesis strategies for the design of plants for the production of supercritical biodiesel. The different configurations (flowsheets) are currently assessed by using commercial chemical process simulators and life cycle assessment (Glisic and Skala, 2009; Deshpande et al., 2010; Lee et al., 2011; Kiwjaroun et al., 2009). Lee et al. (2011) evaluated three continuous biodiesel processes, including a conventional alkali-catalyzed process using both fresh and waste vegetable oil and a supercritical methanol process using waste vegetable oil as the raw material and reported that the alkali-catalyzed process using fresh vegetable oil had the lowest total capital investment, but the supercritical process was the most economically feasible overall, providing a lower manufacturing cost and higher net present value and a discounted cash flow rate of return. Deshpande et al. (2010) reported an economic analysis of the proposed supercritical process and found that the biodiesel processing cost through the proposed technology could be half of that of the current conventional methods.

The assessment of impacts on the environment by supercritical methanol and alkaline catalysis in biodiesel production processes using LCA (life cycle assessment) as a tool was reported by Kiwjaroun et al. (2009). It was observed by these researchers that the SC method is advantageous compared to the conventional method due to the lower amount of wastewater generated; however, it creates a high impact on the environment, emphasizing the need for research regarding the reduction in operating conditions (temperature, pressure) and the amount of alcohol used in the process.

\section{Intensification Technologies in Continuous Mode for SCM}

In the transesterification of vegetable oils, the reaction rate can be limited by mass transfer between oil and alcohol because of the very poor mutual miscibility. Hence, some process intensification technologies have been developed and applied to improve mixing and mass/heat transfer between the two liquid phases in recent years. Some of the technologies have been applied successfully in commercial production (Qiu et al., 2010) where the reaction rate is greatly enhanced and thus residence time may be reduced. To reduce the limitations of mass and heat transfer in chemical reactions, literature recommends to conduct such reactions in micro-reactors (Pohar and Plazl, 2008; Hessel et al., 2005; Wen et al., 2009) and in packed bed reactors (Yu et al., 2010; Santacesaria et al., 2011; Su, 2011) or assisted reaction with hydrodynamic cavitation (Gogate et al., 2008; Sedahmed et al., 2011; Gole et al., 2012), microwave (Gole and Gogate, 2013) and ultrasound (Gole and Gogate, 2012; Gole and Gogate, 2013; Gobikrishnan et al., 2013).

In microreactors, mass and heat transfer increase due to the small size and large contact area (Pohar and Plazl, 2008) and the small internal diameters (typically $10-300 \mu \mathrm{m}$ ) promote interaction with the reagents at the molecular level (Hessel et al., 2005). Guan et al. (2009) used reactors with different inner diameters: $0.04,0.06,0.08$ and $0.1 \mathrm{~cm}$, calling them as microtube reactors. Higher conversion and selectivity were obtained in a shorter reaction time as compared to batch system. Wen et al. (2009) reported the influence of the main geometric parameters on the performance of the zigzag micro-channel reactors in the continuous alkali-catalyzed biodiesel synthesis. The authors concluded that the high reaction efficiency of the zigzag micro-channel reactor can be attributed to the intensification of the overall volumetric mass transfer by passive mixing at the microscale. The experimental results show that smaller channel size and more turns favor the formation of smaller droplets, which results in higher efficiency of biodiesel synthesis. Silva et al. (2010) developed a microtube reactor (internal diameter of $0.76 \mathrm{~mm}$ ) to 
evaluate the effects of inner diameter on the FAEE yield and compared the results with those reported by Silva et al. (2007) for the same conditions using a tubular reactor (internal diameter of $3.2 \mathrm{~mm}$ ). It was reported that, at the lowest temperature $(523 \mathrm{~K})$, only $3.12 \mathrm{wt} \%$ FAEE yield was obtained in the tubular reactor, while $19 \mathrm{wt} \%$ was reached using the microtube reactor. At $598 \mathrm{~K}$ this yield is increased from $38 \mathrm{wt} \%$ to $53 \mathrm{wt} \%$ when changing from the tubular to the microtube reactor at the same residence time. Trentin et al. (2011b) showed the influence of the internal diameter of the reactor for the transesterification of soybean oil under supercritical conditions and reported that the microtube reactor with a smaller inner diameter, $0.571 \mathrm{~mm}$, afforded slightly higher FAEE contents compared to the microreactor with internal diameter of $0.775 \mathrm{~mm}$.

The packed bed system maximizes the interfacial surface area between the two phases (oil and alcohol) and the contact of the two immiscible liquid-liquid phases is improved, achieving excellent mass transfer performance by extruding one phase into the other as the two phases flow through the particles openings, as commonly found in a packed bed reactor (Yu et al., 2010; Santacesaria et al., 2011; Su, 2011; Santacesaria et al., 2012).

Yu et al. (2010) conducted alkali-catalyzed biodiesel synthesis using a reactor packed with metal foam. The metal foam reactor with higher pore density produced smaller droplets and resulted in higher efficiency of biodiesel synthesis and lower energy consumption when compared to the zigzag micro-channel and conventional stirred reactors. Santacesaria et al. (2012) developed a very simple laboratory device for evaluating the behavior of the transesterification reaction in microchannels of different sizes. The technique employed a tubular reactor filled with stainless steel spheres of different diameters and it was shown that high conversions in very short residence times can be reached with such a scheme. In the work of Andrade (2012) a packedbed tubular reactor (PBTR) was developed made of stainless steel tubing (316 L 1/4 in OD inner diameter $3.2 \mathrm{~mm}$ ) and stainless steel tubing (304 L 30.5 $\mathrm{mm}$ OD inner diameter $13 \mathrm{~mm}$ HIP) packed with glass beads ( $4.5 \mathrm{~mm}$ diameter). Results obtained by the authors demonstrate that much higher FAEE yields can be achieved with this configuration when compared to a tubular reactor and microtube reactor. The increased performance of the reaction in the PBTR may possibly be due to the maximized interfacial surface area between the two flowing phases.

Recently, the work of Gobikrishnan et al. (2013) showed that the severity of the supercritical reactions was reduced by including sonication prior to the reaction. The authors reported that the mixture was sonicated at high intensity and a frequency of $40 \mathrm{kHz}$ for $60 \mathrm{~min}$ at $308 \mathrm{~K}$ prior to transesterification by supercritical methanol in batch-mode to reduce the mass-transfer resistance between the oil and alcohol phases and the hence minimize harsh reaction conditions.

\section{Addition of Co-Solvent}

The use of co-solvents in the reaction medium reduces the limitations of mass transfer between the phases involved and increases the reaction rate (Cao et al., 2005; Han et al., 2005). As co-solvents in supercritical transesterification, it has been suggested to use non-polar compressed gases, for example, carbon dioxide, methane, ethane, propane, n-butane and their mixtures (Ginosar et al., 2006). Some studies have also reported the use of heptane/hexane (Imahara et al., 2009; Tan et al., 2010; Muppaneni et al., 2012; Jiang and Tan, 2012) and cyclohexane, dimethyl ether, ether and toluene as co-solvent (Jiang and Tan, 2012).

Cao et al. (2005) and Han et al. (2005) studied the potential use of carbon dioxide and propane as cosolvents in batch mode ester production. Yin et al. (2007) reported that the ester yield for the reaction using supercritical methanol increased when using $\mathrm{CO}_{2}$ as cosolvent. In the alcoholysis of canola oil in methanol with the addition of supercritical $\mathrm{CO}_{2}$, Imahara et al. (2009) found that the addition of cosolvent increased the reaction yield; however, a higher molar percentage of $\mathrm{CO}_{2}$ (above $0.1 \mathrm{CO}_{2} /$ methanol) led to a decrease in reaction conversion. The use of n-heptane as cosolvent was reported by Tan et al. (2010) and the results showed that the addition of a small amount ( 0.2 molar ratio) of n-heptane to methanol had a significant influence on the reaction yield of palm oil with supercritical methanol. Muppaneni et al. (2012) showed the influence of the addition of n-hexane in the ethanolysis of camelina oil and found that the maximum yield was obtained with the addition of $0.2 \mathrm{n}$-hexane to oil volume ratio.

For reactions in continuous mode, Bertoldi et al. (2009) proposed the addition of $\mathrm{CO}_{2}$ as co-solvent in the reaction medium and observed that the FAEE yield decreased with increasing addition of $\mathrm{CO}_{2}$ to the system. At $623 \mathrm{~K}, 20 \mathrm{MPa}$, oil to ethanol molar ratio of 1:40 and $35 \mathrm{~min}$, about an $80 \%$ ester yield was observed for system without co-solvent (Silva et al., 2007) and about $40 \%$ for addition of a $\mathrm{CO}_{2}$ to substrate mass ratio of $0.05: 1$. Considering the increased reaction rates and improved mass transfer 
between phases in the conduction of reactions in a microtube reactor, Trentin et al. (2011a) evaluated the addition of carbon dioxide on the reaction medium of transesterification under supercritical conditions carried out in a microtube reactor. Results showed that the FAEE yields obtained increased with increasing addition of carbon dioxide to the system and the highest yields were obtained with addition of a co-solvent to substrate mass ratio of $0.2: 1$ to the reaction medium. The authors reported that the differences verified regarding the tubular reactor (Bertoldi et al, 2009) can be attributed to mass transfer problems in the tubular reactor and to the fact that mass and heat transfer may be greatly enhanced due to the smaller internal space (which means higher fluid velocity at the same flow rate), and the higher surface area-to-volume ratio, leading to higher process yields.

\section{Two-Step Reaction}

Transesterification under supercritical conditions can be conducted by making use of alternative systems in order to lower raw material and operating costs. There is a growing emphasis on the proposed system with a two-step reaction using reactors in series, with higher conversions compared to the system in one step (Minami and Saka, 2006) at mild operating temperatures and pressures and decreasing the amount of alcohol used in the process (Crawford et al., 2007).

Kusdiana and Saka (2004b) and Minami and Saka (2006) proposed the continuous synthesis of biodiesel from canola oil in two reaction steps, which consist primarily of the hydrolysis of triglycerides in pressurized water and subsequent esterification of fatty acids in supercritical methanol, with glycerol removed prior to FFA methyl esterification. This process is carried out under more moderate temperature and pressure compared to the one step process.

For supercritical transesterification, tubular reactors must operate to minimize the axial dispersion, and this condition can be satisfied by a separation step of unreacted products, with recycle in the same or two or more reactors in series with intermediate separation of the glycerol generated (Busto et al., 2006). One advantage of removing the glycerol formed in the reaction mixture is to allow the reaction to occur at lower ratios of alcohol to oil increasing the reaction rate for the production of biodiesel (Crawford et al., 2007). As cited by Aimaretti et al. (2009), during the reaction, the alcohol used in the process is required by secondary reactions, which occur with glycerol.

D'Ippolito et al. (2007) evaluated theoretically the SCM for producing biodiesel from experimental data and information available in the literature to determine an operating mode and operating conditions that reduce energy consumption and increase product quality. The results obtained suggest that the twostep process with intermediate removal of glycerol decreases the ratios of methanol to oil by about 1015 times. Furthermore, the system pressure can be reduced, as well as energy costs. In the process proposed by Crawford et al (2007), it is suggested that the esters obtained by SCM can be made by transesterification of triglycerides with continuous removal of glycerol formed in the process, periodically or continuously, increasing the rate of ester formation. These authors argued that the reaction conducted in this way can greatly decrease the amount of alcohol used in the process. Another important point of the conduction of reactions in two steps is that the unreacted products, diglycerides and monoglycerides, as well as the esters formed, may act as co-solvents in the reaction medium, increasing the mutual solubility between the phases (Busto et al., 2006).

The transesterification reaction conducted in two steps, two-series reactors and a reactor with recycle is reported by Silva et al. (2011) and Silva et al. (2012) using a tubular and microtube reactor, respectively. The results obtained by the authors reported higher yields for the system in two stages (with intermediate separation of the glycerol generated), with low decomposition of fatty acids. Furthermore, glycerol was obtained with $\sim 90 \mathrm{wt} \%$ purity (after evaporation of ethanol and simple decantation) for the system with recycle. This fact should of course be taken into account for the purpose of implementation of a cost-effective transesterification process (Silva et al., 2012).

\section{Patent Overview on Biodiesel Production Through SCM}

A compilation of the main patents registered over the last 10 years regarding the application of the supercritical method without the use of catalyst is shown in Table 2, which presents the production mode, substrates used and a brief description of the characteristics of each process adopted. It can be seen from the information presented in Table 2 that the patents for the application of this methodology, in most reports, include the technologies described above. Given the number of papers published in the area, patents are still scarce. 
Table 2: Summary of patents on biodiesel through SCM.

\begin{tabular}{|c|c|c|c|}
\hline Reference & Substrates & Production Mode & Brief Description \\
\hline WO2006/121584 A2 & $\begin{array}{l}\text { triglyceride or } \\
\text { FFA/ alcohol }\end{array}$ & Continuous & $\begin{array}{l}\text { Addition of a nonpolar expanding gas (such as carbon dioxide, } \\
\text { methane, ethane, propane, butane) which is dissolved into the } \\
\text { alcohol and used the cosolvent. }\end{array}$ \\
\hline KR2007/0068292 & $\begin{array}{l}\text { vegetable } \\
\text { oils/methanol }\end{array}$ & Continuous & $\begin{array}{l}\text { Comprises the esterifying a vegetable oil in the presence of a } \\
\text { supercritical lower alcohol and a supercritical solvent with a } \\
\text { boiling point similar to that of the lower alcohol. }\end{array}$ \\
\hline WO2007/142983 A2 & $\begin{array}{l}\text { vegetable } \\
\text { oils/alcohol }\end{array}$ & Continuous & Comprising feeding two flows (alcohol and oil) to a microreactor. \\
\hline WO2008/101200 A2 & seed oil/alcohol & & $\begin{array}{l}\text { The reactor allows mixing of the seed oil with the alcohol under } \\
\text { conditions to transesterify the seed oil, the reactor having an outlet; } \\
\text { a power source that operates on a biofuel energy source to produce } \\
\text { heated exhaust. }\end{array}$ \\
\hline US2009/0277077 A1 & $\begin{array}{l}\text { triglyceride (oil } \\
\text { or fat)/alcohol }\end{array}$ & Continuous & $\begin{array}{l}\text { The substrates are re-cycled through a series of heat exchangers } \\
\text { which transfer heat to respective pre-heaters to sequentially raise } \\
\text { the temperature and pressure of the reaction prior to delivery to the } \\
\text { reactor. }\end{array}$ \\
\hline WO2009/002880 A1 & $\begin{array}{l}\text { triglyceride or } \\
\text { fatty acid/alcohol }\end{array}$ & Continuous & $\begin{array}{l}\text { The invention comprised in a vessel for producing biodiesel with a } \\
\text { sealable input; a body that surrounds an interior, wherein said body } \\
\text { is sufficiently robust to withstand a temperature }>573 \mathrm{~K} \text { and a } \\
\text { pressure }>10 \mathrm{MPa} \text {; a porous structure, occupies more than half of } \\
\text { the volume of said interior; and flow control system. }\end{array}$ \\
\hline US2009/7524982 B2 & $\begin{array}{l}\text { vegetable } \\
\text { oils/ethanol or } \\
\text { methanol }\end{array}$ & Continuous & $\begin{array}{l}\text { The reaction occurs a tube reactor and the resulting product is } \\
\text { directed to the reservoir at the reactor outlet where an upper phase } \\
\text { of alcohol is recycled, and the intermediate phase, biodiesel, and } \\
\text { the lower phase (mostly of glycerin) are led to the separation } \\
\text { reservoir. }\end{array}$ \\
\hline US2010/7772414 B1 & $\begin{array}{l}\text { biological } \\
\text { material (oil } \\
\text { seeds)/alcohol }\end{array}$ & Continuous & $\begin{array}{l}\text { Comprises extracting lipids from the biological material with a } \\
\text { supercritical alcohol in an extractor, passing the extract directly } \\
\text { into a reactor for transesterification reaction. }\end{array}$ \\
\hline WO2010/090965 & $\begin{array}{l}\text { FFA or } \\
\text { glycerides/ } \\
\text { methanol }\end{array}$ & Batch & $\begin{array}{l}\text { The method uses an electrostatic probe to provide an electrical } \\
\text { field within the reactor. This causes the glycerin molecules to } \\
\text { precipitate out of the feedstock mixture. }\end{array}$ \\
\hline KR2010/0110678 & $\begin{array}{l}\text { vegetable } \\
\text { oils/alcohol }\end{array}$ & Batch & $\begin{array}{l}\text { The method used an ultrasonic wave-supercritical fluid reactor for } \\
\text { biodiesel production. }\end{array}$ \\
\hline CN2011/101935593 & $\begin{array}{l}\text { vegetable } \\
\text { oils/methanol }\end{array}$ & Continuous & $\begin{array}{l}\text { The method is characterized in that: methanol and oil are pumped } \\
\text { into a static mixer according by a metering pump and mixed by the } \\
\text { static mixer to enter a tubular reactor for reaction in the } \\
\text { supercritical state. }\end{array}$ \\
\hline US2011/8052848 B2 & $\begin{array}{l}\text { vegetable oils } \\
\text { with high } \\
\text { FFA/alcohol }\end{array}$ & Batch or continuous & $\begin{array}{l}\text { The method comprising the steps of: providing a reaction mixture } \\
\text { (alcohol and oil); inputting microwave energy into said reaction } \\
\text { mixture; and inputting ultrasonic energy into said reaction mixture. }\end{array}$ \\
\hline CN2012/102559374 & $\begin{array}{l}\text { microalgae/ } \\
\text { methanol }\end{array}$ & Batch & $\begin{array}{l}\text { The invention comprises a one-step method where the methanol } \\
\text { and solid catalyst are added into algae powder, and the reaction } \\
\text { was performing in a high pressure kettle under heating. }\end{array}$ \\
\hline CN2012/102533450 & $\begin{array}{l}\text { vegetable } \\
\text { oils/methanol }\end{array}$ & Continuous & $\begin{array}{l}\text { The invention discloses a process in two-step which comprises: }(1) \\
\text { hydrolyzing an oil mixture under the subcritical water condition; } \\
\text { and (2) performing methylation on the under the supercritical } \\
\text { condition. }\end{array}$ \\
\hline
\end{tabular}

FFAs: free fatty acids. 


\section{FUTURE PERSPECTIVES}

The production of biodiesel by the non-catalytic supercritical method was described and reviewed in this report. This process shows strong advantages over conventional techniques that justify its implementation; nevertheless, studies considering the technical and economical limitations of the method must be performed. These studies should consider: i) the identification of compounds formed from decomposition of the constituents of the reaction medium and the influence on the characteristics of the biofuel generated; ii) establishment of reactors configurations operated in continuous mode aiming to increase mass transfer and ester yield under milder operating conditions; iii) investigation of different substrates (raw materials) for the transesterification reaction under supercritical conditions. The analysis of these points may be crucial for the purpose of large-scale use of supercritical technology in transesterification reactions.

\section{ACKNOWLEDGEMENTS}

The authors thank CNPq, CAPES, Fundação Araucária and Maringa State University (UEM) for the financial support and scholarships.

\section{REFERENCES}

Abbaszaadeh, A., Ghobadian, B., Omidkhah, M. R., Najafi, G., Current biodiesel production technologies: A comparative review. Energy Conversion and Management, 63, 138-148 (2012).

Agência Nacional do Petróleo, Gás Natural e Biocombustíveis, Boletim mensal de biodiesel. Brasília, Brazil, Agência Nacional de Petróleo, Gás Natural e Biocombustíveis, January; p. 9, Retrieved from http://www.anp.gov.br (2012). (In Portuguese). (Accessed: April 19, 2013).

Al-Dhubabian, A., Jovanovic, G. N., Parjer, J., Paul, B. K., Microreactor process for making biodiesel. WO Patent 142983 A2 (2007).

Aimaretti, N., Manuale, D. I., Mazzieri, V. M., Vera, C. R., Yori, C., Batch study of glycerol decomposition in one-stage supercritical production of biodiesel. Energy \& Fuel, 23, 1076-1080 (2009).

Altin, R., Çetinkaya, S., Yucesu H, S., The potential of using vegetable oil fuels as fuel for diesel engines. Energy Conversion \& Management, 42, 529-538 (2001).

Anderson, G., Vessels and methods for synthesis of biofuel. WO Patent 002880 A1 (2009).

Anitescu, G., Taylarides, L., Integrated multistage supercritical technology to produce high quality vegetable oils and biofuels. WO Patent 101200 A2 (2008).

Andrade, S. B., Produção contínua de ésteres etílicos a partir do óleo de soja utilizando etanol supercrítico em leito estruturado. MSc. Thesis, Universidade Estadual de Maringá, Brazil (2012). (In Portuguese).

Anitescu, G., Deshpande, A., Tavlarides, L. L., Integrated technology for supercritical biodiesel production and power cogeneration. Energy \& Fuel, 22, 1391-1399 (2008).

Bertoldi, C., Silva, C., Bernardon, J. P., Corazza, M. L., Cardozo-Filho, L., Oliveira, J. V., Corazza, F. C., Continuous production of biodiesel from soybean oil in supercritical ethanol and carbon dioxide as co-solvent. Energy \& Fuels, 23, 5165-5172 (2009).

Boer, K., Bahri, P. A., Supercritical methanol for fatty acid methyl ester production: A review. Biomass and Bioenergy, 35, 983-991 (2011).

Bunyakiat, K., Makmee, S., Sawangkeaw, R., Ngamprasertsith, S., Continuous production of biodiesel via transesterification from vegetable oils in supercritical methanol. Energy \& Fuels, 20, 812-817 (2006).

Busto, M., D' Ippolito, S. A., Yori, J. C., Iturria, M. E., Pieck, C. L., Grau, J. M., Vera, C. R., Influence of the axial dispersion on the performance of tubular reactors during the non-catalytic supercritical transesterification of triglycerides. Energy \& Fuels, 20, 2642-2647 (2006).

Cao, W., Han, H., Zhang, J., Preparation of biodiesel from soybean oil using supercritical methanol and co-solvent. Fuel, 84, 347-351 (2005).

Choi, C., Kim, J., Jeong, C., Kim, H, Yoo, K., Transesterification kinetics of palm olein oil using supercritical methanol. The Journal of Supercritical Fluids, 58, 365-370 (2011).

Crawford, J. W., Crawford, J. M., Crafts, R., Transesterification of oil to form biodiesel. United States Patent, 059512 (2007).

Dall'Agnol, A., Dariva, C., Nascimento Sobrinho, E. R., Baldus, A. O., Oliveira, J. V., Process for the production of biodiesel in continuous mode without catalysts. US Patent 7524982 B2 (2009).

Demirbas, A., Biodiesel from vegetable oils via transesterification in supercritical methanol. Energy Conversion \& Management, 43, 2349-2356 (2002).

Deshpande, A., Anitescu, G., Rice, P. A., Tavlarides, L. L., Supercritical biodiesel production and power cogeneration: Technical and economic feasibil- 
ities. Bioresource Technology, 101, 1834-1843 (2010).

D’Ippolito, S. A., Yori, J. C., Iturria, M. E., Pieck, C. L., Vera, C. R., Analysis of a two-step, noncatalytic, supercritical biodiesel production process with heat recovery. Energy \& Fuels, 21, 339-346 (2007).

Du, Y., Liu, M., Yang, Q., Method for preparing biodiesel from microalgae through one-step method by utilizing supercritical methanol. CN Patent 102559374 (2012).

Fang, T., Li, Y., Xu, J., Process for preparing biodiesel through supercritical methanol two-step method of heat integration coupling flash evaporation. CN Patent 102533450 (2012).

Fox, R. V., Ginosar, D., Petkovic, L. M., Production of biodiesel using expanded gas solvents. WO Patent 121584 A2 (2006).

Fukuda, H., Kondo, A., Noda, H., Biodiesel fuel production by transesterification of oils. Journal of Bioscience and Bioengineering, 92, 405-416 (2001).

Ginosar, D., Fox, R., Petkovic, L. M., Christian, S., Production of biodiesel using expanded gas solvents. United States Patent:121584 (2006).

Gleason, R. J., Worrell, A. S., Biodiesel fuel and method of manufacture therefor. WO Patent 0277077 A1 (2009).

Glisic, S., Skala, D., The problems in design and detailed analyses of energy consumption for biodiesel synthesis at supercritical conditions. The Journal of Supercritical Fluids, 49, 293-301 (2009).

Gobikrishnan, S., Park, J., Park, S., Indrawan, N., Rahman, S. F., Park, D., Sonication-assisted production of biodiesel using soybean oil and supercritical methanol. Bioprocess and Biosystems Engineering, 36, 705-71 (2013).

Gogate, P. R., Cavitational reactors for process intensification of chemical processing applications: A critical review. Chemical Engineering and Processing: Process Intensification, 47, 515527 (2008).

Gole, V. L., Gogate, P. R., A review on intensification of synthesis of biodiesel from sustainable feed stock using sonochemical reactors. Chemical Engineering and Processing: Process Intensification, 53, 1-9 (2012).

Gole, V. L., Naveen, K. R., Gogate, P. R., Hydrodynamic cavitation as an efficient approach for intensification of synthesis of methyl esters from sustainable feedstock. Chemical Engineering and Processing: Process Intensification, In Press, Corrected Proof (2012).
Gole, V. L., Gogate, P. R., Intensification of synthesis of biodiesel from non-edible oil using sequential combination of microwave and ultrasound. Fuel Processing Technology, 106, 62-69 (2013).

Guan, G., Kusakabe, K., Moriyama, K., Sakurai, N., Transesterification of sunflower oil with methanol in a microtube reactor. Industrial \& Engineering Chemistry Research, 48, 1357-1363 (2009).

Han, H., Cao, W., Zhang, J., Preparation of biodiesel from soybean oil using supercritical methanol and $\mathrm{CO}_{2}$ as co-solvent. Process Biochemistry, 40, 3148-3151 (2005).

Hwang, J. S., Yoo, K. P., Method for preparing biodiesel using supercritical alcohol and solvent. KR Patent 0068292 (2007).

He, H., Tao, W., Zhu, S., Continuous production of biodiesel from vegetable oil using supercritical methanol process. Fuel, 86, $442-447$ (2007).

Helwani, Z., Othman, M. R., Aziz, N., Fernando, W. J. N., Kim, J., Technologies for production of biodiesel focusing on green catalytic techniques: A review. Fuel Processing Technology, 90, 15021514 (2009).

Hessel, V., Hardt, S., Lowe, H., Chemical Micro Process Engineering: Fundamentals, Modelling and Reactions. Editora Wiley-VCH Verlag: Germany (2005).

Hybertson, B. M., Hansen, B. N., Process for producing biodiesel fuel products. US Patent 7772414 B1 (2010).

Imahara, H., Minami, E., Hari, S., Saka, S., Thermal stability of biodiesel in supercritical methanol. Fuel, 87, 1-6 (2008).

Imahara, H., Xin, J., Saka, S., Effect of $\mathrm{CO}_{2} / \mathrm{N}_{2}$ addition to supercritical methanol on reactivities and fuel qualities in biodiesel production. Fuel, 88, 1329-1332 (2009).

Jiang, J., Tan, C., Biodiesel production from coconut oil in supercritical methanol in the presence of co-solvent. Journal of the Taiwan Institute of Chemical Engineers, 43, 102-107 (2012).

Kasim, N. S., Tsai, T., Gunawan, S., Ju, Y., Biodiesel production from rice bran oil and supercritical methanol. Bioresource Technology, 100, 2399-2403 (2009).

Kiss, F. E., Jovanović, M., Bošković, G. C., Economic and ecological aspects of biodiesel production over homogeneous and heterogeneous catalysts. Fuel Processing Technology, 91, 1316-1320 (2010).

Kiwjaroun, C., Tubtimdee, C., Piumsomboon, P., LCA studies comparing biodiesel synthesized by conventional and supercritical methanol methods. Journal of Cleaner Production, 17, 143-153 (2009). 
Kropf, M. M., Ultrasonic and microwave methods for enhancing the rate of a chemical reaction and apparatus for such methods. US Patent 8052848 B2 (2011).

Kusdiana, D., Saka, S., Biodiesel fuel from rapeseed oil as prepared in supercritical methanol. Fuel, 80, 225-231 (2001).

Kusdiana, D., Saka, S., Effects of water on biodiesel fuel production by supercritical methanol treatment. Bioresource Technology, 91, 289-295 (2004a).

Kusdiana, D., Saka, S., Two-step preparation for catalyst-free biodiesel fuel production. Applied Biochemistry and Biotechnology, 115, 781-791 (2004b).

Lam, M. K., Lee, K. T., Mohamed, A. R., Homogeneous, heterogeneous and enzymatic catalysis for transesterification of high free fatty acid oil (waste cooking oil) to biodiesel: A review. Biotechnology Advances, 28, 500-518 (2010).

Lee, S., Posarac, D., Ellis, N., Process simulation and economic analysis of biodiesel production processes using fresh and waste vegetable oil and supercritical methanol. Chemical Engineering Research and Design, 89, 2626-2642 (2011).

Lee, S., Posarac, D., Ellis, N., An experimental investigation of biodiesel synthesis from waste canola oil using supercritical methanol. Fuel, 91, 229-237 (2012).

Marchetti, J. M., Errazu, A. F., Technoeconomic study of supercritical biodiesel production plant. Energy Conversion \& Management, 49, 21602164 (2008).

Marulanda, V. F., Anitescu, G., Tavlarides, L. L., Investigations on supercritical transesterification of chicken fat for biodiesel production from low cost lipid feedstocks. The Journal of Supercritical Fluids, 54, 53-60 (2010).

McCormick, R. L., Graboski, M. S., Alleman, T. L., Herring, A. M., Impact of biodiesel source material and chemical structure on emissions of criteria pollutants from a heavy-duty engine. Environmental Science \& Technology, 35, 17421747 (2001).

Meher, L. C., Vidya, S. D., Naik, S. N., Technical aspects of biodiesel production by transesterification: A review. Renewable and Sustainable Energy Reviews, 10, 248-268 (2006).

Miller, D., Method of producing biodiesel with supercritical alcohol and apparatus for same. WO Patent 090965 (2010).

Minami, E., Saka, S., Kinetics of hydrolysis and methyl esterification for biodiesel production in two-step supercritical methanol process. Fuel, 85, 2479-2483 (2006).

Muppaneni, T., Reddy, H. K., Patil, P. D., Dailey, P., Aday, C., Deng, S., Ethanolysis of camelina oil under supercritical condition with hexane as a cosolvent. Applied Energy, 94, 84-88 (2012).

Ngamprasertsith, S., Sawangkeaw, R., Transesterification in Supercritical Conditions. In: Biodiesel - Feedstocks and Processing Technologies. Rijeka: InTech, 247-268 (2011).

Olivares-Carrillo, P., Quesada-Medina, J., Synthesis of biodiesel from soybean oil using supercritical ethanol in a one-step catalyst-free process in batch reactor. The Journal of Supercritical Fluids, 58, 378-384 (2011a).

Olivares-Carrillo, P., Quesada-Medina, J., Evidence of thermal decomposition of fatty acid methyl esters during the synthesis of biodiesel with supercritical methanol. The Journal of Supercritical Fluids, 56, 56-63 (2011b).

Olivares-Carrillo, P., Quesada-Medina, J., Thermal decomposition of fatty acid chains during the supercritical methanol transesterification of soybean oil to biodiesel. The Journal of Supercritical Fluids, 72, 52-58 (2012).

Pinnarat, T., Savage, P., Assessment of noncatalytic biodiesel synthesis using supercritical reaction conditions. Industrial \& Engineering Chemistry Research, 47, 6801-6808 (2008).

Pohar, A., Plazl, I., Laminar to turbulent transition and heat transfer in a microreactor: Mathematical modeling and experiments. Industrial \& Engineering Chemistry Research, 47, 7447-7455 (2008).

Qiu, Z., Zhao, L., Weatherley, L., Process intensification technologies in continuous biodiesel production. Chemical Engineering and Processing, 49, 323-330 (2010).

Robles-Medina, A., González-Moreno, P. A., EstebanCerdán, L., Molina-Grima, E., Biocatalysis: Towards ever greener biodiesel production. Biotechnology Advances, 27, 398-408 (2009).

Ranganathan, S. V., Narasimhan, S. L., Muthukumar, $\mathrm{K}$., An overwiew of enzymatic production of biodiesel. Bioresource Technology, 99, 3975-3981 (2008).

Ryu, J. H., Lim, G. B., Jung, I. I., An apparatus for producing biodiesel using ultrasound-assisted supercritical fluid and method thereof. KR Patent 0110678 (2010).

Santacesaria, E., Di Serio, M., Tesser, R., Tortorelli, M., Turco, R., Russo, V., A simple device to test biodiesel process intensification. Chemical Engineering and Processing, 50, 1085-1094 (2011). 
Santacesaria, E., Di Serio, M., Tesser, R., Turco, R., Tortorelli, M., Russo, V., Biodiesel process intensification in a very simple microchannel device. Chemical Engineering and Processing: Process Intensification, 52, 47-54 (2012).

Sawangkeaw, R., Teeravitud, S., Bunyakiat, K., Ngamprasertsith, S., Biofuel production from palm oil with supercritical alcohols: Effects of the alcohol to oil molar ratios on the biofuel chemical composition and properties. Bioresource Technology, 102, 10704-10710 (2011).

Sedahmed, G. H., El-Taweel, Y. A., Konsowa, A. H., Abdel-Aziz, M. H., Mass transfer intensification in an annular electrochemical reactor by an inert fixed bed under various hydrodynamic conditions. Chemical Engineering and Processing: Process Intensification, 50, 1122-1127 (2011).

Silva, C., Weschenfelder, T. A., Rovani, S., Corazza, F. C., Corazza, M. L., Dariva, C., Oliveira, J. V., Continuous production of fatty acid ethyl esters from soybean oil in compressed ethanol. Industrial \& Engineering Chemistry Research, 46, 5304-5309 (2007).

Silva, C., Castilhos, F., Oliveira, J. V., CardozoFilho, L., Continuous production of soybean biodiesel with compressed ethanol in a microtube reactor. Fuel Processing Technology, 91, 1274-81 (2010).

Silva, C., Lima, A. P., Castilhos, F., Cardozo Filho, L., Oliveira, J. V., Non-catalytic production of fatty acid ethyl esters from soybean oil with supercritical ethanol in a two-step process using a microtube reactor. Biomass \& Bioenergy, 35, 526-532 (2011).

Silva, C., Borges, G., Castilhos, F., Oliveira, J. V., Cardozo Filho, L., Continuous production of fatty acid ethyl esters from soybean oil at supercritical conditions. Acta Scientiarum. Technology, 34, 185-192 (2012).

Shin, H., Lim, S., Bae, S., Oh, C., Thermal decomposition and stability of fatty acid methyl esters in supercritical methanol. Journal of Analytical and Applied Pyrolysis, 92, 332-338 (2011).

Srivastava, A., Prasad, R., Triglycerides-based diesel fuels. Renewable and Sustainable Energy Reviews, 4, 111-133 (2000).

$\mathrm{Su}, \mathrm{Y}$., The intensification of rapid reactions for multiphase systems in a microchannel reactor by packing microparticles. AIChE Journal, 57, 14091418 (2011).

Tan, K. T., Lee, K. T., Mohamed, A. R., Effects of free fatty acids, water content and co-solvent on biodiesel production by supercritical methanol reaction. The Journal of Supercritical Fluids, 53, 88-91 (2010).

Trentin, C. M., Lima, A. P., Alkimim, I. P., Silva, C., Castilhos, F., Mazutti, M. A., Oliveira, J. V., Continuous production of soybean biodiesel with compressed ethanol in a microtube reactor using carbon dioxide as co-solvent. Fuel Processing Technology, 92, 952-958 (2011a).

Trentin, C. M., Lima, A. P., Alkimim, I. P., Silva, C., Castilhos, F., Mazutti, M. A., Oliveira, J. V., Continuous catalyst-free production of fatty acid ethyl esters from soybean oil in microtube reactor using supercritical carbon dioxide as co-solvent. The Journal of Supercritical Fluids, 56, 283-291 (2011b).

Vieitez, I., Silva, C., Borges, G. R., Corazza, F. C., Oliveira, J. V., Grompone, M. A., Jachmanián, I., Continuous production of soybean biodiesel in supercritical ethanol-water mixtures. Energy \& Fuels, 22, 2805-2809 (2008).

Vieitez, I., Silva, C., Alkimim, I., Borges, G. R., Corazza, F. C., Oliveira, J. V., Grompone, M. A., Jachmanián, I., Effect of temperature on the continuous synthesis of soybean esters under supercritical ethanol. Energy \& Fuels, 23, 558-563 (2009).

Vieitez, I., Silva, C., Alkimim, I., Borges, G. R., Corazza, F. C., Oliveira, J. V., Grompone, M. A., Jachmanián, I., Continuous catalyst-free methanolysis and ethanolysis of soybean oil under supercritical alcohol/water mixtures. Renewable Energy, 35, 1976-1981 (2010).

Vieitez, I., Pardo, M. J., Silva, C., Bertoldi, C., Castilhos, F., Oliveira, J. V., Grompone, M. A., Jachmanián, I., Continuous synthesis of castor oil ethyl esters under supercritical ethanol. The Journal of Supercritical Fluids, 56, 271-276 (2011).

Vieitez, I., Irigaray, B., Casullo, P., Pardo, M., Grompone, M. A., Jachmanián, I., Effect of free fatty acids on the efficiency of the supercritical ethanolysis of vegetable oils from different origins. Energy \& Fuels, 26, 1946-1951 (2012).

Velez, A., Soto, G., Hegel, P., Mabe, G., Pereda, S., Continuous production of fatty acid ethyl esters from sunflower oil using supercritical ethanol. Fuel, 97, 703-709 (2012).

Vyas, A. P., Verma, J. L., Subrahmanyam, N., A review on FAME production processes. Energy \& Fuel, 89, 1-9 (2010).

$\mathrm{Xu}, \mathrm{R}$., Method for preparing biodiesel by adopting supercritical methanol continuous process. CN Patent 101935593 (2011).

Wang, C., Zhou, J., Chen, W., Wang, W., Wu, Y., Zhang, J., Chi, R., Ying, W., Effect of weak acids as a catalyst on the transesterification of soybean 
oil in supercritical methanol. Energy \& Fuels, 22, 3479-3483 (2008).

Warabi, Y., Kusdiana, D., Saka, S., Reactivity of triglycerides and fatty acids of rapeseed oil in supercritical alcohols. Bioresource Technology, 91, 283-287 (2004).

Wen, Z., Yu, X., Tu, S., Yan, J., Dahlquist, E., Intensification of biodiesel synthesis using zigzag micro-channel reactors. Bioresource Technology, 100, 3054-3060 (2009).
Yin, J., Xiao, M., Song, J. B., Biodiesel from soybean oil in supercritical methanol with co-solvent. Energy Conversion \& Management, 49, 908-912 (2007).

Yu, X., Wen, Z., Lin, Y., Tu, S., Wang, Z., Yan, J., Intensification of biodiesel synthesis using metal foam reactors. Fuel, 89, 3450-3456 (2010).

Zhang, Y., Dubé, M. A., MClean, D. D., Kates, M., Biodiesel production from waste cooking oil. Bioresource Technology, 89, 1-16 (2003). 